\title{
Designing a Mixed Digital Signage and Multi-touch Interaction for Social Learning
}

\author{
Long-Chyr Chang and Heien-Kun Chiang \\ Information Management Department and \\ Graduate Institue of Digital Content Technology \& Management, \\ National Changhua University of Education, Taiwan \\ \{lcchang, hkchiang\} @cc.ncue.edu.tw
}

\begin{abstract}
Recently, digital signage has been getting popular in public and private environments, such as retail stores, museums, corporate buildings and even campuses. Digital signage with large and vivid LCD display is typically used as public information exhibition. In spite of growing popularity of digital signage, the lack of interactive capabilities of conventional digital signage prevents students from further exploring and sharing information on the display for learning purpose. Multi-touch interaction with large display, on the other hand, provides natural and intuitive interfaces that can potentially attract students to engage and play in public space. However, how to design a multi-touch application to engage students in a natural and playful learning environment still remains less unexplored research area because it requires developing a new innovation of hardware and software complexity.

In this paper, we present a mixed digital signage and multi-touch interaction environment that can encourage students engaging in a watch-and-play style social learning at a public place. The system was designed and developed by transforming two VIZIO 52-inch LCD displays into a multi-touch social learning space with little extra cost. The two LCD displays are designed to function as a typical digital signage to show interesting news and video to attract students outside our department. Students then can point their fingers on displays and turn the system into a multi-touch Web-based rich multimedia learning environment.

To realize the key factors of student engagement and satisfaction with our system, we developed a user study model based on the updated D \& M IS Success Model and the Technology Acceptance Model. The integrated model contains six constructs: system quality, information quality, interaction quality, perceived usefulness, perceived ease-of-use, and user satisfaction. Empirical result from 145 participants indicates our proposed system is very promising. However, user study on our research model also validated some system design problems such as system and interaction quality must be solved to make the proposed system as a great learning aid in the foreseeable future. The evaluation model we developed can be used as an evaluation tool to provide useful guidelines for developing more advanced social learning system. The software architecture, implication, and future work were described.
\end{abstract}

Keywords: Multi-touch, Digital Signage, Social Learning. 